\title{
Primary Common Bile Duct Closure Is Safe Following Emergency and Elective Exploration
}

\author{
Nikhil Pawa $\cdot$ Matthew G. Tutton
}

Published online: 17 April 2009

(C) Société Internationale de Chirurgie 2009

We read with interest the study by Ahmed et al. [1] reviewing the need for T-tube placement following common bile duct exploration [1]. We agree with their findings and conclusions to reserve T-tube placement for incomplete ductal clearance and for those patients with difficult access for endoscopic retrograde cholangiopancreatography (ERCP). However, we also feel it is just as imperative to clarify the use of primary closure in the emergency setting.

A retrospective review was performed in our unit of all cases of primary closure following a laparoscopic common bile duct exploration from a prospectively collated database. A total of 81 cases (24 males, 57 females) between 1992 and 2006 were identified. The median age within this group was 66 (range $=22-90)$ years. From this group $60(74 \%)$ patients underwent primary closure following exploration in the elective setting and 21 (26\%) patients in the emergency setting. The presence of jaundice was confirmed preoperatively in $33 \%$ of the elective subgroup, and $38 \%$ of the emergency subgroup, and deranged liver function tests in $40 \%$ of the elective group and $43 \%$ of the emergency group. Preoperative ultrasound examination identified common bile duct calculi, or a dilated duct in $37 \%$ of the elective patients and $52 \%$ of the emergency patients. An on-table cholangiogram was performed in 74 cases, and laparoscopic common bile duct exploration was successfully performed in 80 patients with one conversion to open. There was no significant difference in the operative time between either group (mean elective $=150 \mathrm{~min}$, emergency $=151 \mathrm{~min}$ ). The mean postoperative hospital stay for the elective subgroup was 4.5 days and that for the emergency subgroup

N. Pawa $(\bowtie) \cdot$ M. G. Tutton

ICENI Centre, Colchester University NHS Foundation Trust,

Turner Road, Colchester, Essex CO4 5JL, UK

e-mail: nikhil@pawa.me.uk was 5.0 days. A total of nine patients (9/81) (elective $=6$, emergency $=3$ ) required an ERCP postoperatively, with three patients developing wound infections. There was no mortality in the total group of patients. These results further support findings of Alhamdani et al. [2] with a lower conversion rate achieved in this series. This confirms that no significant difference exists in the outcome measures between patients following primary closure of the common bile duct in either the elective or the emergency setting, and in the hands of an experienced laparoscopic surgeon this method is both safe and efficient.

Furthermore, we were also concerned with the lack of use of the transcystic approach for exploration of the common bile duct by the authors. This method has been reported to achieve a high frequency of stone clearance $(85 \%)$ with low morbidity and a shorter hospital stay. Therefore, it has been proposed to be an effective method for patients with smaller ductal stones [3]. The authors are kindly asked to comment on this issue.

\section{References}

1. Ahmed I, Pradhan C, Beckingham IJ et al (2008) Is a T-tube necessary after common bile duct exploration? World J Surg 32:1458-1485

2. Alhamdani A, Mahmud S, Jameel M et al (2008) Primary closure of choledochotomy after emergency laparoscopic common bile duct exploration. Surg Endosc 22:2190-2195

3. Stromberg C, Nilsson M, Leijonmarck CE (2008) Stone clearance and risk factors for failure in laparoscopic transcystic exploration of the common bile duct. Surg Endosc 22:1194-1199 